\title{
Pengaruh Beban dan Filter Pada Penyearah AC-DC Terkendali Untuk Rangkaian Pengisi Li-ion Berbasis Bridge Rectifier dan Buck Converter Menggunakan Metode $\mathrm{CC} / \mathrm{CV}$
}

\author{
Alif Pradana Hakim ${ }^{*}$, Sena Sukmananda Suprapto ${ }^{2}$, Mifta Nur Farid ${ }^{3}$ \\ Program Studi Teknik Elektro, Jurusan Teknologi Industri dan Proses, Institut Teknologi Kalimantan, \\ Balikpapan, Indonesia
}

Email:04161007@student.itk.ac.id

\begin{abstract}
Lately, lots of electronic devices using battery as its power source such as handphone and laptop. A battery charger has AC (Alternating Current) source need an AC to DC (Direct Current) converter. The output of $A C$ $D C$ converter is not suitable for CC/CV (Constant Current/Constant Voltage) charging method, a buck converter is required to produce the desired value. Moreover, the AC-DC conversion is carrying ripples, which could damage the battery and affect the rectification ratio $(R R)$, filters are required to reduce the ripple and increase the RR. The experiment has been conducted on CC 1,5A and CV 4,2V using load variations. On CC, the increment of load cause increment of duty cycle. On CV, the increment of load cause the decrement of duty cycle. The use of filter on $C C$ and $C V$ are able to decrease ripple and increase RR. On CC, mathematic, simulation, and practical results are decrement of ripple value respectively, 46,45\%, 46,43\%, and 45,46\%. While RR are increasing respectively, $18,17 \%, 18,17 \%$, and $21,59 \%$. While on $C V$, the mathematic, simulation, and practical ripple are decreasing as much as $46,44 \%, 46,6 \%$, and $48,78 \%$. While $R R$ on CV are increasing as much as 18,17\%, 18,17\%, and 20,99\%. The Li-ion charging took 4 hours 58 seconds to complete. The CC charging took 32 minutes and 10 seconds and CV charging took 3 hours 28 minutes 48 seconds. On CC charging, duty cycle will increase when the battery voltage is increasing. Whereas on $C V$, the duty cycle will decrease when the charging current is decreasing.
\end{abstract}

Keyword: AC-DC Converter, Constant Current, Constant Voltage.

\begin{abstract}
Abstrak
Saat ini, banyak perangkat elektronik yang menggunakan baterai sebagai sumber dayanya seperti handphone dan laptop. Sebuah charger baterai yang bersumber AC (Alternating Current) memiliki sebuah penyearah AC ke DC (Direct Current). Keluaran penyearah AC-DC tidak sesuai untuk pengisian CC/CV (Constant Current/Constant Voltage), sehingga diperlukan buck converter untuk menghasilkan nilai yang diinginkan. Selain itu, penyearahan AC-DC membawa ripple yang dapat merusak baterai dan mempengaruhi rectification ratio (RR), sehingga memerlukan filter untuk mengurangi ripple dan meningkatkan rectification ratio. Percobaan dilakukan pada kondisi arus konstan atau CC 1,5A dan kondisi tegangan konstan atau CV 4,2V menggunakan variasi beban. Pada percobaan CC, diketahui bahwa peningkatan beban akan menyebabkan peningkatan duty cycle yang dibutuhkan. Pada uji coba $\mathrm{CV}$, diperoleh hasil bahwa peningkatan beban menyebabkan pengurangan duty cycle yang dibutuhkan. Penggunaan filter pada kondisi CC dan CV dapat mengurangi ripple dan meningkatkan RR. Pada kondisi CC, ripple matematis, simulasi, dan uji coba secara berturut-turut berkurang $46,45 \%, 46,43 \%$, dan $45,46 \%$. RR matematis, simulasi, dan uji coba secara berturut-turut meningkat $18,17 \%, 18,17 \%$, dan $21,59 \%$. Pada kondisi CV, ripple matematis, simulasi, dan uji coba secara berturut-turut berkurang $46,44 \%, 46,6 \%$, dan $48,78 \%$. RR matematis, simulasi, dan uji coba secara berturut-turut meningkat $18,17 \%, 18,17 \%$, dan $20,99 \%$. Pengisian Li-ion 3Ah memakan waktu 4 jam 58 detik. Dimana pengisian CC selama 32 menit 10 detik dan pengisian $\mathrm{CV}$ selama 3 jam 28 menit 48 detik. Pada pengisian $\mathrm{CC}$ duty cycle meningkat saat terjadinya peningkatan tegangan baterai. Sedangkan pada pengisian $\mathrm{CV}$, duty cycle menurun saat berkurangnya arus pengisian.
\end{abstract}

Kata Kunci: Constant Current, Constant Voltage, Penyearah AC- DC. 


\section{Pendahuluan}

Baterai Li-ion (Lithium Ion) adalah sumber listrik bagi revolusi elektronik digital di masyarakat modern, khususnya pada handphone dan laptop [1]. Baterai Liion adalah baterai sekunder yang dayanya dapat diisi ulang. Untuk mengisi baterai tersebut dapat digunakan sebuah pengisi daya yang bersumber AC (Alternating Current) dan memiliki sebuah converter AC ke DC (Direct Current) yang terdiri dari sebuah trafo step-down dan rectifier bridge konvensional [2].

Pada penyearah bridge digunakan empat buah dioda untuk melakukan penyearahan gelombang tegangan tanpa memerlukan center-tapped trafo [3]. Ketika tegangan AC dikonversi menjadi DC menggunakan rectifier, tegangan keluaran DC membawa komponen AC yang tidak diinginkan yang disebut dengan ripple. Banyak pengaplikasian penyearah yang memerlukan agar ripple tidak melewati nilai yang ditetapkan dan saat ripple melewati nilai tersebut akan muncul hal-hal yang tidak diinginkan seperti rugirugi panas, audible noise, dan lain-lain. Ripple ini dapat dikurangi menggunakan sebuah filter [4].

Selain itu, nilai ripple pada converter dapat mempengaruhi rectification ratio (RR). RR merupakan cara untuk mengetahui efektivitas dari penyearah, nilai ini diperoleh dengan perbandingan nilai DC yang dihasilkan oleh converter dengan nilai DC yang dipengaruhi oleh ripple [3].

Bridge rectifier hanya berfungsi untuk mengubah tegangan $\mathrm{AC}$ menjadi tegangan DC saja dan tidak mampu mengubah level tegangan, sehingga untuk menghasilkan level tegangan yang diinginkan diperlukan rangkaian tambahan. Rangkaian yang dapat mengatur level tegangan $\mathrm{DC}$ disebut sebagai DC-DC converter. DC-DC converter memiliki konfigurasi dasar seperti buck, boost, dan buck-boost converter [5]. Buck converter berfungsi untuk menghasilkan tegangan keluaran yang lebih rendah dibandingkan tegangan masukannya.
Rangkaian yang digunakan untuk mengisi baterai Li-ion memiliki regulasi tegangan dengan toleransi lebih tinggi $\pm 1 \%$ sebagaimana yang direkomendasikan oleh manufaktur baterai untuk memaksimalkan performa baterai Li-ion. Metode pengisian untuk baterai Li-ion adalah metode $\mathrm{CC} / \mathrm{CV}$ (Constant Current/Constant Voltage) [6]. Pada pengisian $\mathrm{CC} / \mathrm{CV}$, fase $\mathrm{CC}$ dan fase $\mathrm{CV}$ dapat saling melengkapi, rugi-rugi kapasitas yang disebabkan oleh besarnya polarisasi elektrokimia pada fase $\mathrm{CC}$ dapat dikompensasi secara efektif pada fase $\mathrm{CV}$. Sehingga, pengisian $\mathrm{CC} / \mathrm{CV}$ menjadi lebih baik dibandingkan pengisian $\mathrm{CC}$ ataupun pengisian CV saja [7].

Pada baterai ini, pengisian $\mathrm{CC}$ biasanya memakan waktu lebih dari 1 jam, sedangkan total waktu pengisian sekitar 3 jam [8]. Pada metode ini, pengisian biasanya dihentikan dengan arus pengisian minimum. Arus minimum memiliki pendekatan arus pengisian saat mode $\mathrm{CV}$ dan menghentikan pengisian ketika arus bernilai $0,02 \mathrm{C}$ sampai $0,07 \mathrm{C}$. Kondisi ini menyiratkan bahwa ripple arus keluaran charger tidak boleh melebihi nilai ini. Besaran nilai ripple pada arus keluaran

sangat penting untuk keandalan performa dan memperpanjang masa penggunaan baterai [6].

Oleh karena itu, pada penelitian ini akan dilakukan analisis terkait pengaruh beban yang diberikan pada duty cycle penyearah AC-DC terkendali saat kondisi constant current (CC), constant voltage (CV). Selain pengaruh beban, dilakukan juga analisis pengaruh filter yang telah dirancang pada ripple dan rectification ratio penyearah AC-DC terkendali, dan juga waktu serta duty cycle yang dibutuhkan saat pengisian baterai Li-ion yang dilakukan oleh penyearah AC-DC terkendali. 


\section{Metoda Penelitian}

\subsection{Blok Diagram Sistem}

Error! Reference source not found. menunjukkan diagram blok dari sistem pengisian yang akan dirancang. Dimulai dengan tegangan masukan $\mathrm{AC}$ pada rangkaian. Kemudian tegangan AC tersebut akan disearahkan oleh bridge rectifier. Tegangan AC yang telah disearahkan oleh bridge rectifier akan diatur dan difilter oleh buck converter dengan PWM dari mikrokontroler sehingga menghasilkan nilai keluaran yang diinginkan. Pada pengisian kendali PWM dari mikrokontroler bersifat closed loop dan mempertimbangkan feedback dari sensor. Selain itu, mikrokontroler pada pengisian juga berfungsi untuk merekam data yang terbaca oleh sensor. Lalu, beban yang digunakan adalah baterai yang akan

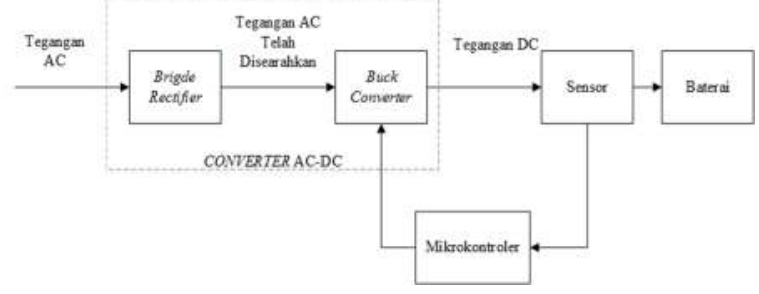

diisi.

Gambar 1. Diagram Blok Sistem

\subsection{Metode Pengisian CC/CV}

Pada penelitian ini dipilih metode pengisian $\mathrm{CC} / \mathrm{CV}$ (Constant Current / Constant Voltage), metode $\mathrm{CC} / \mathrm{CV}$ adalah penggabungan dari pengisian arus konstan (CC) dan pengisian tegangan konstan (CV). Pada pengisian ini, sebuah baterai akan diisi dengan arus konstan yang telah ditentukan pada fase $\mathrm{CC}$ dan tegangan baterai akan meningkat hingga mencapai nilai maksimum yang aman. Lalu, baterai akan memasuki fase $\mathrm{CV}$ dengan tegangan konstan yang telah ditentukan, menyebabkan arus pengisian kontinyu menurun. Fase CV akan berakhir ketika arus yang berkurang mencapai nilai tertentu atau kapasitas tujuan telah tercapai [8].

Rangkaian yang digunakan untuk mengisi baterai Li-ion memiliki regulasi tegangan dengan toleransi lebih tinggi $\pm 1 \%$ sebagaimana yang direkomendasikan memaksimalkan performa baterai Li-ion. Metode pengisian untuk baterai Li-ion adalah metode $\mathrm{CC} / \mathrm{CV}$ (Constant Current/Constant Voltage). Pada metode ini, pengisian biasanya dihentikan dengan arus pengisian minimum. Arus minimum memiliki pendekatan arus pengisian saat mode $\mathrm{CV}$ dan menghentikan pengisian ketika arus bernilai 0,02C sampai 0,07C. Kondisi ini menyiratkan bahwa ripple arus keluaran charger tidak boleh melebihi nilai ini. Besaran nilai ripple pada arus keluaran sangat penting untuk keandalan performa dan memperpanjang masa penggunaan baterai [6].

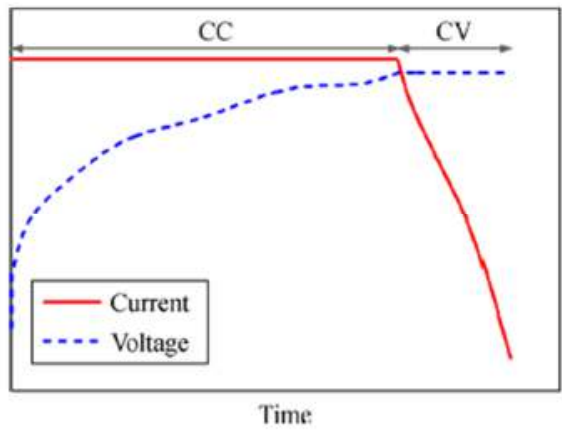

Gambar 1. Kurva Pengisian CC/CV [8]

\subsection{Bridge Rectifier Dengan PWM}

Pada Gambar 2 adalah bridge rectifier konvensional yang menggunakan empat buah dioda. Selama setengah siklus positif dari tegangan sekunder trafo, arus akan mengalir menuju beban dari dioda D1 dan D2. Selama setengah siklus negatif, D3 dan D4 akan mengalami konduksi. Bridge rectifier tersusun dari sebuah trafo, empat buah dioda, dan sebuah beban resistif $\mathrm{R}$ [3]. Bridge recitifer dapat digabungkan dengan metode pemotongan sinyal seperti PWM (Pulse Width Modulation). Pemotongan sinyal juga dapat digunakan untuk mengubah model matematis dari sebuah sinyal. Pada metode ini, tegangan keluaran dari bridge rectifier akan "dipotong" menggunakan sebuah urutan dengan sejumlah pulsa dan duty cycle untuk mengendalikan aliran arus menuju beban. Teknik ini menawarkan kendali linear untuk komponen DC dan dapat mendistribusikan komponen AC (ripple) 


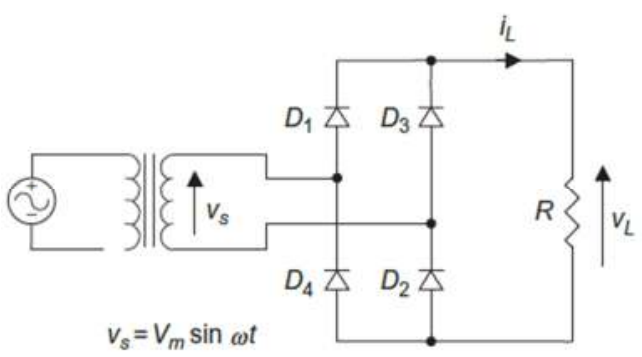

Gambar 2. Bridge Rectifier Konvensional [3]

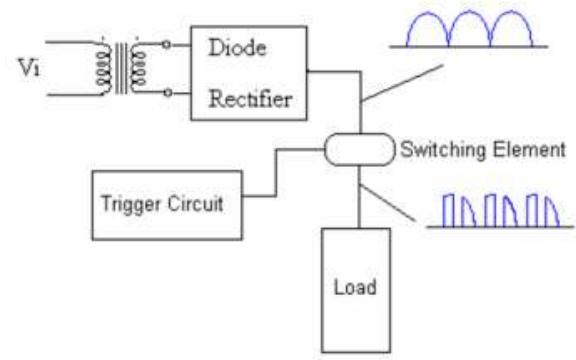

Gambar 3. Bridge Rectifier dengan PWM [9]

Pada penelitian ini, digunakan tegangan masukan 9VAC dengan frekuensi $50 \mathrm{~Hz}$, serta frekuensi penyaklaran $50 \mathrm{kHz}$. Untuk duty cycle kondisi CC pada beban $1 \Omega$ dengan tegangan awal 9VAC dan arus target 1,5ADC didapatkan dengan persamaan [9] dan [11].

$$
\begin{aligned}
& D=\frac{1,5 \times \pi}{1 \times 2 \times 9 \sqrt{2}} \\
& =0,185=18,5 \%
\end{aligned}
$$

Nilai duty cycle yang diperlukan untuk kondisi $\mathrm{CV}$ dengan sumber 9VAC dan menghasilkan tegangan keluaran 4,2V dapat diperoleh dengan [9].

$$
D=\frac{4,2 \times \pi}{2 \times 9 \sqrt{2}}=0,518=51,8 \%
$$

\subsection{Ripple Factor}

Pada sebuah bridge rectifier dengan PWM, nilai ripple dapat diperoleh dengan menggunakan deret Fourier. Hal ini

dikarenakan ripple setelah penyaklaran memiliki gelombang nonperiodik [10]. Deret Fourier memiliki elemen sinyal pada fungsi $\cos \left(a_{n}\right)$ dan sin $\left(b_{n}\right)$. Pada penyearah gelomang penuh elemen deret Fourier yang mempengaruhi
Diperoleh elemen deret Fourier untuk order 2 dengan menggunakan tegangan masukan 9VAC, frekuensi ripple $100 \mathrm{~Hz}$, frekuensi penyaklaran $50 \mathrm{kHz}$, dan duty cycle pada persamaan (2) [10].

$$
\begin{gathered}
a_{2}=\frac{2}{\pi} \sum_{k=0}^{\frac{50.000}{100}-1} \\
{\left[\int_{\frac{100 \times k \times \pi}{50.000}}^{\frac{100 \times \pi}{50.000}(k+0,518)} 9 \sqrt{2} d(\theta)\right]} \\
=\frac{-2,8 \mathrm{~V}}{\frac{50.000}{100}-1} \\
{\left[\int_{\frac{100 \times k \times \pi}{50.000}}^{\frac{100 \times \pi}{50.000}(k+0,518)}\right.} \\
=-4 \times 10^{-8} \mathrm{~V}
\end{gathered}
$$

Sinyal sin dan cos dari frekuensi yang sama dapat dikombinasikan dalam sebuah sinusoid, hal ini mengakibatkan jumlah sinyal $a_{2}$ dan $b_{2}$ menjadi [3].

$$
\begin{gathered}
C_{2}=\sqrt{2,8^{2}+4 \times 10^{-8^{2}}} \\
=2,8 \mathrm{~V}
\end{gathered}
$$

Diperoleh nilai ripple sebesar [3].

$$
\begin{gathered}
\text { ripple }=\frac{2,8}{\sqrt{2} \times 4,2} \\
=0,4714=47,14 \%
\end{gathered}
$$

\subsection{Rectification Ratio}

Rectification ratio atau rasio penyearahan adalah cara untuk mengetahui efektivitas dari penyearah [3]. Nilai ini dapat diperoleh dengan nilai pada persamaan (5), nilai tegangan target $4,2 \mathrm{~V}$, dan persamaan pada [3].

$$
\begin{aligned}
R R & =\frac{4,2^{2}}{\left(\sqrt{\left(\frac{2,8}{\sqrt{2}}\right)^{2}+4,2^{2}}\right)^{2}} \\
& =0,81818=81,82 \%
\end{aligned}
$$

\subsection{Filter Induktor}

Penggunaan induktor berfungsi untuk mencegah arus meningkat terlalu tinggi 
menggunakan filter induktor tidak akan menghasilkan tegangan sebesar filter kapasitor. Namun, kekurangan ini teratasi karena filter induktor dapat menghasilkan arus yang lebih tinggi tanpa perubahan yang signifikan pada tegangan keluarannya. Hal ini yang menjadikan filter induktor cocok untuk pengaplikasian daya tinggi [4]. Karena filter induktor terhubung seri dengan beban, nilai ripple dengan menggunakan filter dipengaruhi oleh [3].

$$
\frac{v_{o}}{v_{L}}=\frac{R}{\sqrt{R^{2}+\left(2 \pi f_{r} L_{f}\right)^{2}}}
$$

Sehingga perancangan filter induktor dengan nilai ripple awal 0,4714 , nilai ripple akhir 0,1, dan beban [11].

$$
\begin{aligned}
R= & \frac{4,2 V}{1,5 A}=2,8 \Omega \\
L= & \frac{2,8 \sqrt{\left(\frac{0,4714}{0,1}\right)^{2}-1}}{2 \pi \times 100} \\
= & 20,5 \mathrm{mH}
\end{aligned}
$$

Dengan menggunakan persamaan untuk lilitan induktor [12] diperoleh banyaknya lilitan untuk nilai induktor tersebut.

$$
\begin{gathered}
N=1000 \sqrt{\frac{20.5}{16 \times 10^{3}}} \\
=35.8 \approx 36 \text { lilitan }
\end{gathered}
$$

Dengan menggunakan persamaan yang sama, diperoleh nilai aktual induktor $20,7 \mathrm{mH}$.

\subsection{Filter Kapasitor}

Penggunaan filter kapasitor setelah filter induktor akan menghasilkan kualitas tegangan dan arus yang tinggi. Kapasitor berfungsi untuk menghaluskan gelombang tegangan sedangkan induktor untuk menghaluskan gelombang arus [4]. Kapasitor terhubung secara paralel dengan beban dan total impedansi kapasitor-beban akan terhubung secara seri dengan induktor. Hal ini menyebabkan persamaan (8) berubah menjadi.

$$
\begin{gathered}
Z_{\text {paralel }}=\frac{1}{\sqrt{\left(\frac{1}{R}\right)^{2}+\left(\frac{1}{X_{C}}\right)^{2}}} \\
\frac{v_{O}}{v_{L}}=\frac{Z_{\text {paralel }}}{\sqrt{Z_{\text {paralel }}^{2}+\left(2 \pi f_{r} L\right)^{2}}}
\end{gathered}
$$

Dimana $Z_{\text {paralel }}$ diperoleh dengan [13]. dan $X_{C}[14]$.

$$
X_{C}=\frac{1}{2 \pi f_{r} C}
$$

Sehingga didapatkan nilai filter kapasitor dengan nilai $\mathrm{R}$ pada persamaan (9), nilai induktor $20,7 \mathrm{mH}$, ripple awal 0,4714, dan ripple akhir 0,01 .

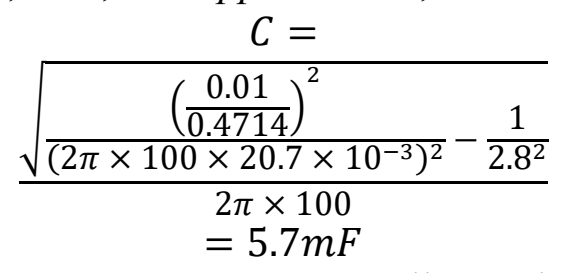

Dengan menyesuaikan komponen yang tersedia, digunakan nilai kapasitor $8,2 \mathrm{mF}$.

\subsection{Buck Converter}

Buck converter adalah sebuah stepdown DC-DC converter yang menghasilkan rata-rata tegangan keluaran lebih rendah dari tegangan masukannya. Pada Gambar 4, sebuah buck converter terdiri dari sumber tegangan DC (Vs), saklar kontrol (S), dioda (D), filter induktor (L), filter kapasitor (C), dan beban resistansi (R). Pada rangkaian ini, ketika saklar S pada keadaan on, dioda D akan mengalami bias mundur. Ketika saklar off, dioda akan mengalami konduksi untuk menyuplai arus yang tak terinterupsi pada induktor [3].

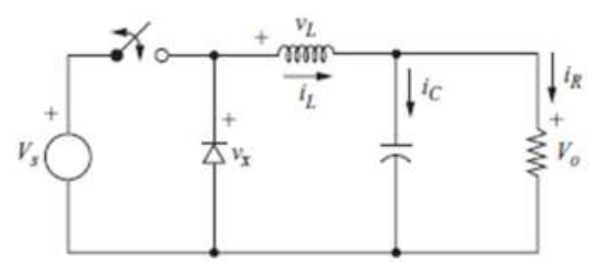

Gambar 4. Buck Converter [10]

\subsection{Rangkaian Penyearah}

Rancangan rangkaian penyearah AC- 
DC terkendali merupakan gabungan dari dua konstruksi rangkaian yang telah ada sebelumnya, yakni bridge rectifier dan buck converter. Didapatkan rangkaian penyearah AC-DC seperti pada Gambar 5

berikut. Diketahui bahwa rangkaian ini terdiri dari sumber tegangan $\mathrm{AC}$, diode bridge yang terdiri dari 4 buah dioda, saklar semi-konduktor, dioda freewheel $\left(D_{F}\right)$, filter induktor $(\mathrm{L})$, filter kapasitor (C), dan beban uji coba.

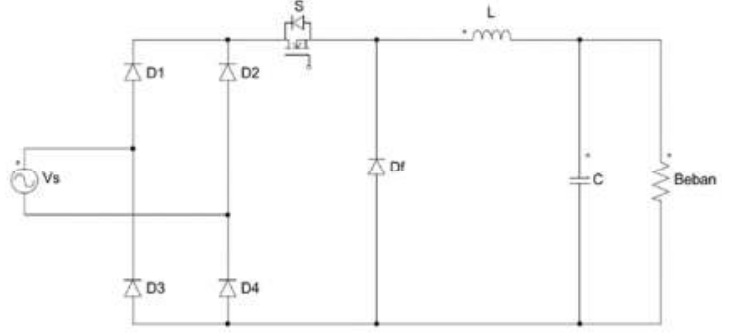

Gambar 5. Rangkaian Penyearah AC/DC

Rangkaian penyearah pada penelitian ini memiliki spesifikasi seperti pada Tabel 1.

Tabel 1 Spesifikasi Alat

\begin{tabular}{|c|c|}
\hline Parameter & Nilai/Tipe \\
\hline Tegangan masukan $\left(V_{S}\right)$ & 9VAC \\
\hline Frekuensi masukan $\left(f_{i}\right)$ & $50 \mathrm{~Hz}$ \\
\hline Tegangan keluaran $\left(V_{O}\right) \mathrm{CV}$ & $4,2 \mathrm{VDC}$ \\
\hline \multicolumn{2}{|c|}{ Tabel 1 Spesifikasi Alat } \\
\hline Parameter & Nilai/Tipe \\
\hline Arus keluaran $\left(I_{O}\right) \mathrm{CC}$ & $1,5 \mathrm{~A}$ \\
\hline Frekuensi switching $\left(f_{s}\right)$ & $50 \mathrm{kHz}$ \\
\hline Kapasitas baterai $(C)$ & $3 \mathrm{Ah}$ \\
\hline Ripple tegangan $(\Delta V)$ & $1 \%$ \\
\hline Ripple arus $(0.05 \mathrm{C})(\Delta I)$ & $10 \%$ \\
\hline \multirow{2}{*}{ Beban Uji Coba CC } & 1,2 dan \\
\hline & \\
\hline \multirow{2}{*}{ Beban Uji Coba CV } & 3,6 , dan \\
\hline & $100 \Omega$ \\
\hline Dioda Penyearah & 1N5822 \\
\hline MOSFET & IRF540N \\
\hline Dioda Freewheel & 1N5822 \\
\hline
\end{tabular}

\section{Hasil Penelitian}

Diperoleh hasil data berdasarkan perhitungan matematis, simulasi, dan uji coba. Dilakukan pembahasan duty cycle pada kondisi CC dan CV untuk

mengetahui pengaruh variasi beban, serta pembahasan ripple dan rectification ratio pada kondisi $\mathrm{CC}$ dan $\mathrm{CV}$ untuk mengetahui pengaruh penggunaan filter.

\subsection{Duty Cycle}

Pulse Wide Modulation (PWM) merupakan metode yang digunakan untuk mengatur lebar sinyal digital. Lebar sinyal ini direpresentasikan sebagai lebar pulsa dalam satu periode waktu. Umumnya PWM memiliki besar amplitudo dan frekuensi dasar yang sama, tetapi dengan lebar pulsa bervariasi. Dengan teknik PWM, beberapa pulsa on dan off akan terbentuk. Persentase pulsa ditampilkan dalam duty cycle dalam rentang 0 hingga $100 \%$.

Pada bagian ini, saat kondisi CC rangkaian akan menghasilkan arus 1,5A dan saat kondisi CV akan menghasilkan tegangan konstan 4,2V. Berdasarkan hasil yang diperoleh, didapatkan arus saat kondisi CC tanpa dan dengan saklar pada Gambar 6. Diketahui bahwa pada matematis, simulasi, dan uji coba dapat diperoleh nilai arus 1,5A dengan nilai awalan yang berbeda-beda. Nilai duty cycle yang dibutuhkan untuk menghasilkan arus 1,5A terdapat pada Gambar 7. Pada Gambar 7 dapat diketahui bahwa pada perhitungan matematis, simulasi, dan uji coba bahwa variasi beban dapat memengaruhi nilai duty cycle yang dibutuhkan. Semakin tinggi nilai beban yang digunakan pada kondisi $\mathrm{CC}$, maka semakin tinggi nilai duty cycle yang dibutuhkan.

Pada kondisi CV, didapatkan hasil perhitungan matematis, simulasi, dan uji coba pada Gambar 8. Pada Gambar 8 tersebut didapatkan hasil tegangan $4,2 \mathrm{~V}$ untuk setiap kondisi beban. Pada hasil perhitungan nilai tegangan keluaran tanpa saklar bernilai sama, hal ini berakibat pada 
duty cycle yang dibutuhkan untuk semua beban bernilai sama. Sedangkan pada simulasi dan uji coba terdapat perbedaan nilai tegangan keluaran tanpa saklar, hal ini menyebabkan duty cycle yang dibutuhkan untuk menghasilkan 4,2V menjadi berbeda.

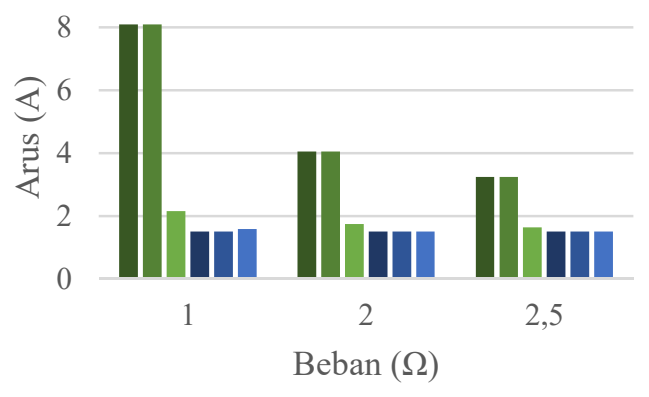

- Matematis Tanpa Saklar - Simulasi Tanpa Saklar

- Uji Coba Tanpa Saklar - Matematis Dengan Saklar

- Simulasi Dengan Saklar Uji Coba Dengan Saklar

Gambar 6. Perbandingan Arus Keluaran Kondisi $\mathrm{CC}$

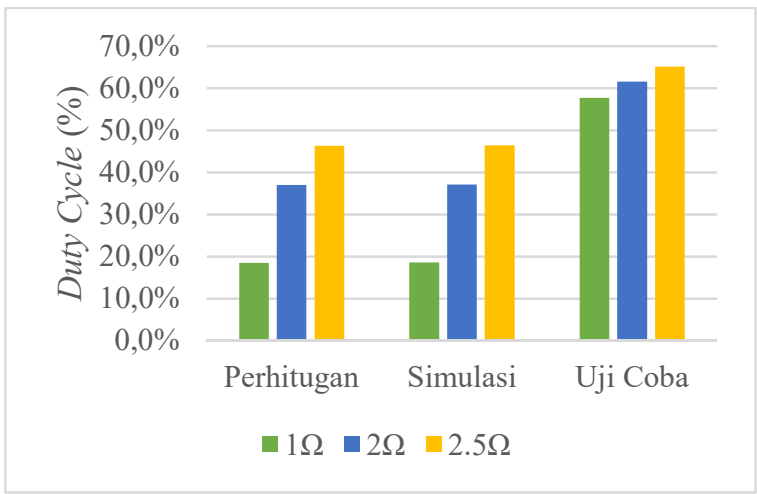

Gambar 7. Perbandingan Duty Cycle Kondisi CC

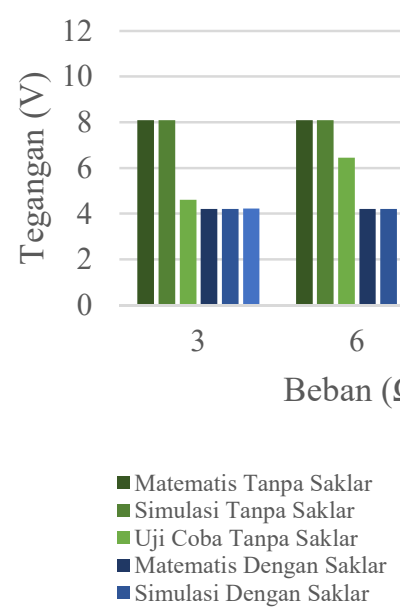

Gambar 8. Perbandingan Tegangan Keluaran Kondisi CV

\subsection{Ripple Factor}

Pada bagian ini dibahas mengenai pengaruh penggunaan filter pada kondisi $\mathrm{CC}$ dan kondisi $\mathrm{CV}$ terhadap nilai ripple yang dihasilkan rangkaian penyearah terkendali. Pada kondisi CC, berdasarkan data yang diperoleh didapatkan nilai rataan ripple matematis tanpa menggunakan filter sebesar $47,14 \%$ dan setelah menggunakan filter sebesar $0,69 \%$ sehingga diperoleh penurunan nilai ripple secara matematis sebesar 46,45\%. Pada hasil simulasi didapatkan nilai rataan ripple tanpa filter sebesar $47,14 \%$ dan dengan menggunakan filter $0,71 \%$.

Diperoleh penurunan ripple secara simulasi sebesar $46,43 \%$. Pada uji coba didapatkan nilai rataan ripple tanpa filter sebesar 53,45\% dan dengan filter sebesar 7,99\%, kemudian dapat diketahui penurunan ripple pada uji coba sebesar $45,45 \%$. Pada uji coba dapat diketahui pada beban $1 \Omega$ filter kapasitor tidak dapat berfungsi, sehingga nilai ripple difilter sepenuhnya dengan filter induktor. Hal ini menyebabkan ripple uji coba pada beban $1 \Omega$ lebih tinggi dibandingkan beban lainnya. Berdasarkan Gambar 10 dapat diketahui bahwa secara perhitungan matematis, simulasi, dan uji coba bahwa penggunaan filter pada kondisi $\mathrm{CC}$ dapat menurunkan ripple pada seluruh variasi beban.

Pada kondisi $\mathrm{CV}$, diperoleh nilai rataan ripple matematis tanpa menggunakan filter sebesar 47,14\% dan setelah menggunakan filter sebesar $0,7 \%$ sehingga diperoleh penurunan nilai ripple secara matematis sebesar 46,44\%. Pada hasil simulasi didapatkan nilai rataan ripple tanpa filter sebesar $47,14 \%$ dan dengan menggunakan filter $0,54 \%$. Diperoleh penurunan ripple secara simulasi sebesar 46,6\%. Pada uji coba didapatkan nilai rataan ripple tanpa filter sebesar $51,8 \%$ dan dengan filter sebesar $3,02 \%$, kemudian dapat diketahui penurunan ripple pada uji coba sebesar 48,78\%. Berdasarkan Gambar 11 dapat diketahui bahwa secara perhitungan matematis, simulasi, dan uji coba bahwa 
penggunaan filter pada kondisi $\mathrm{CV}$ dapat menurunkan ripple pada seluruh variasi beban meskipun tidak mencapai $1 \%$.

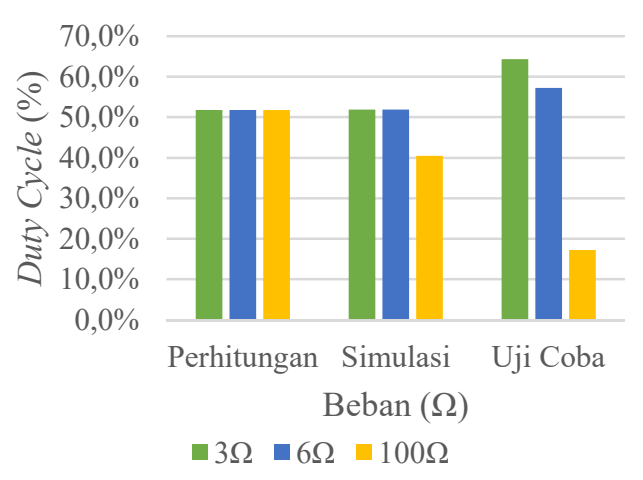

Gambar 9. Perbandingan Duty Cycle Kondisi CV

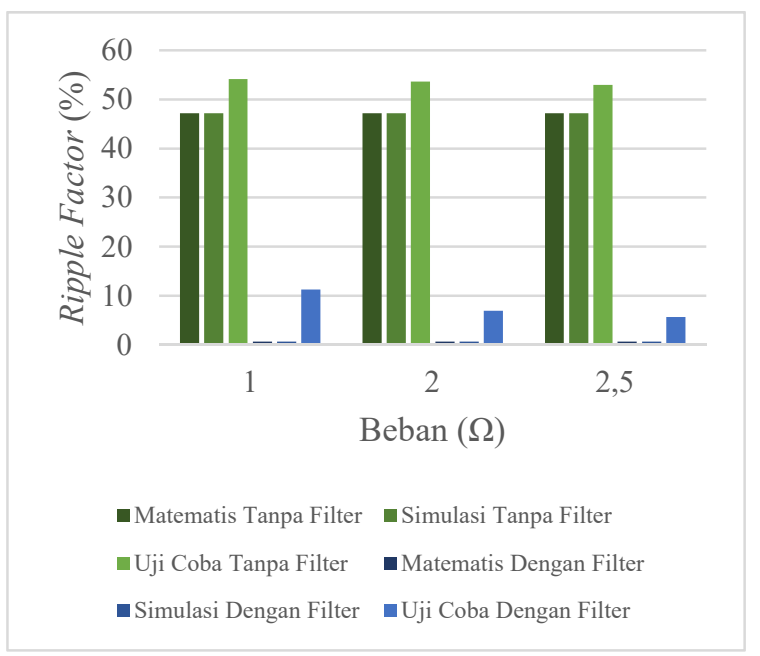

Gambar 10. Perbandingan Ripple Kondisi CC

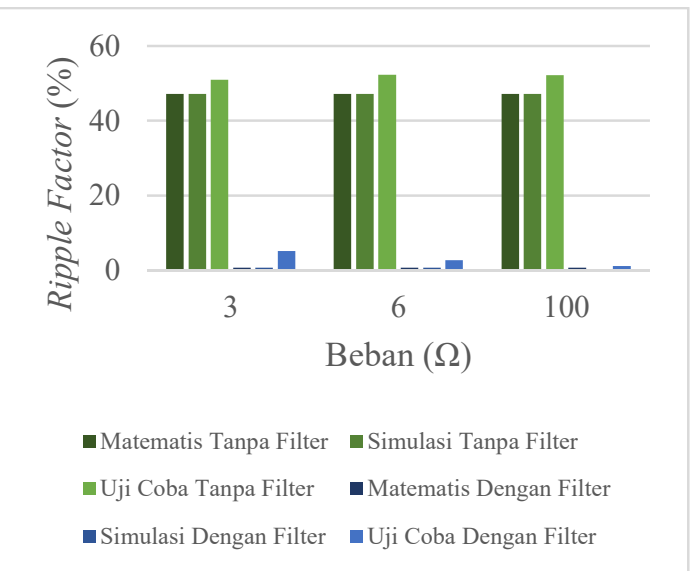

Gambar 11. Perbandingan Ripple Kondisi CV

\subsection{Rectification Ratio}

Pada bagian ini dibahas mengenai pengaruh penggunaan filter pada kondisi
$\mathrm{CC}$ dan kondisi $\mathrm{CV}$ terhadap nilai rectification ratio ( $\mathrm{RR})$ yang dihasilkan rangkaian penyearah terkendali. Pada kondisi CC, berdasarkan data yang diperoleh didapatkan nilai rataan $R R$ matematis tanpa menggunakan filter sebesar $81,82 \%$ dan setelah menggunakan filter sebesar 99,99\% sehingga diperoleh peningkatan nilai RR secara matematis sebesar 18,17\%. Pada hasil simulasi didapatkan nilai rataan RR tanpa filter sebesar $81,82 \%$ dan dengan menggunakan filter 99,99\%. Diperoleh peningkatan RR secara simulasi sebesar $18,17 \%$.

Pada uji coba didapatkan nilai rataan ripple tanpa filter sebesar $77,72 \%$ dan dengan filter sebesar 99,31\%, kemudian dapat diketahui peningkatan RR pada uji coba sebesar $21,59 \%$. Pada uji coba $1 \Omega$ diperoleh nilai RR setelah filter terendah dengan nilai $98,75 \%$, sehingga dapat dikatakan efisiensi penyearahan rangkaian ini pada kondisi CC melebihi 98\%.

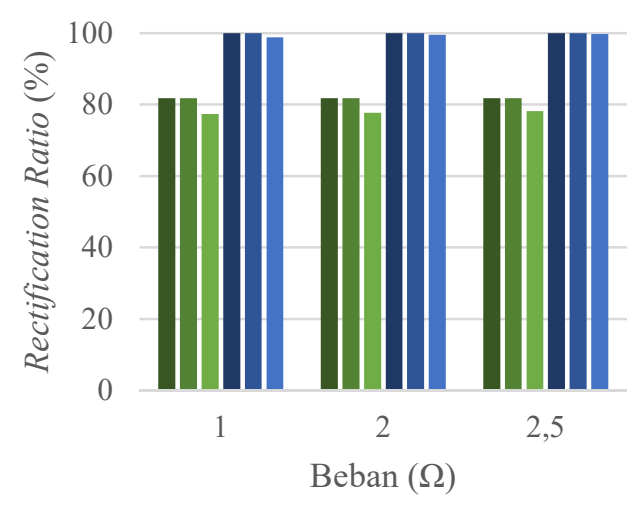

$$
\begin{aligned}
& \text { - Matematis Tanpa Filter } \quad \text { Simulasi Tanpa Filter } \\
& \text {-Uji Coba Tanpa Filter } \quad \text { Matematis Dengan Filter } \\
& \text { - Simulasi Dengan Filter } \quad \text { - Uji Coba Dengan Filter }
\end{aligned}
$$

Gambar 12. Perbandingan RR Kondisi CC

Pada kondisi CV, berdasarkan data yang diperoleh didapatkan nilai rataan $\mathrm{RR}$ matematis tanpa menggunakan filter sebesar $81,82 \%$ dan setelah menggunakan filter sebesar 99,99\% sehingga diperoleh peningkatan nilai RR secara matematis sebesar 18,17\%. Pada hasil simulasi didapatkan nilai rataan RR tanpa filter sebesar $81,82 \%$ dan dengan menggunakan filter 99,99\%. Diperoleh peningkatan RR secara simulasi sebesar $18,17 \%$. Pada uji coba didapatkan nilai rataan ripple tanpa 
filter sebesar 78,84\% dan dengan filter sebesar 99,83\%, kemudian dapat diketahui peningkatan RR pada uji coba sebesar $20,99 \%$. Pada uji coba $3 \Omega$ diperoleh nilai RR setelah filter terendah dengan nilai $99,73 \%$, sehingga dapat dikatakan efisiensi

penyearahan rangkaian ini pada kondisi CV melebihi 99\%.

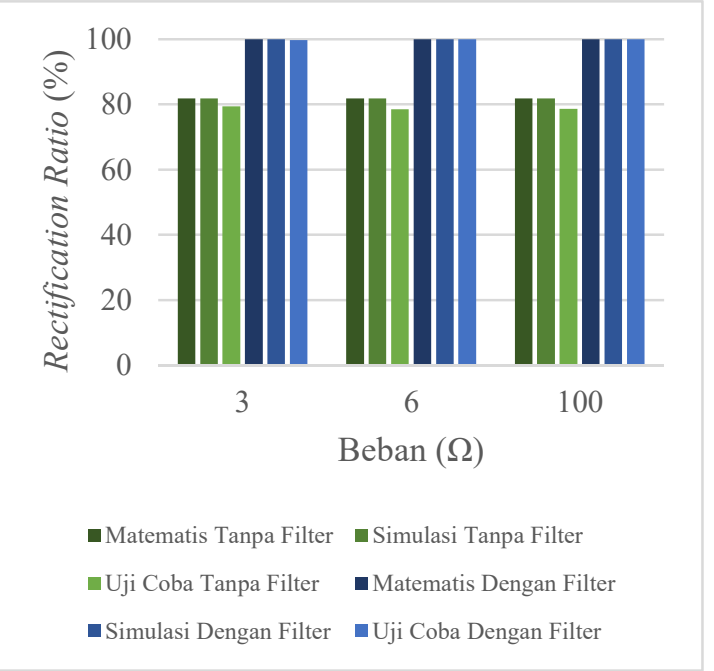

Gambar 13. Perbandingan RR Uji Coba Kondisi $\mathrm{CV}$

\subsection{Pengisian Baterai Li-ion}

Rangkaian yang telah dirancang digunakan untuk mengisi baterai Li-ion LG HG2 dengan kapasitas 3Ah. Berdasarkan pengisian baterai yang telah dilakukan, didapatkan grafik pengisian baterai seperti pada Gambar 14 dan grafik duty cycle pada Gambar 15. Berdasarkan gambar tersebut, dapat dilihat bahwa pengisian baterai dimulai pada tegangan $3,64 \mathrm{~V}$, arus $1,05 \mathrm{~A}$, dan duty cycle $61,96 \%$. Pengisian dimulai pada detik 31 sampai detik 14489, sehingga didapatkan waktu pengisian selama 14458 detik atau setara dengan 4 jam 58 detik. Pada detik 31 sampai detik 1960 merupakan pengisian arus konstan. Pada pengisian ini, duty cycle diatur agar dapat menghasilkan arus keluaran senilai 1,5A. Tetapi, ketika tegangan baterai mencapai $4,1 \mathrm{~V}$ pada detik 1239, nilai arus yang mampu dihasilkan oleh rangkaian menjadi lebih rendah dibandingkan 1,5A dan rangkaian tidak mampu menaikkan arus agar mencapai nilai $1,5 \mathrm{~A}$. Hal ini disebabkan oleh sumber yang tidak ideal dan terbatas, sehingga walaupun duty cycle sudah mencapai nilai maksimum seperti pada Gambar 15 nilai arus tidak dapat ditingkatkan lagi.

Pada detik 1962 sampai detik 14489, pengisian dilakukan dengan kondisi tegangan konstan (CV). Duty cycle diatur agar rangkaian dapat mengisi dengan nilai tegangan konstan 4,2V. Pada Gambar 15, dapat diketahui bahwa terjadi penurunan nilai duty cycle yang digunakan dan sejalan dengan menurunnya nilai arus pengisian. Pengisian berakhir dengan nilai tegangan $4,2 \mathrm{~V}$, arus $0,06 \mathrm{~A}$, dan duty cycle $18,82 \%$.

Berdasarkan gambar 14 dan gambar 15, dapat diketahui bahwa pengisian baterai Li-ion dengan kondisi CC terjadi selama 1929 detik atau 32 menit 10 detik dan pengisian dengan kondisi CV selama 3 jam 28 menit 48 detik. Sehingga dapat diketahui bahwa pengisian dengan kondisi CV pada baterai Li-ion memakan waktu yang lebih lama dibandingkan pengisian CC. Selain itu, dapat diketahui bahwa pada pengisian $\mathrm{CC}$ akan terjadi peningkatan nilai duty cycle yang terjadi karena peningkatan nilai tegangan baterai. Sedangkan pada pengisian $\mathrm{CV}$, nilai duty cycle akan menurun sejalan dengan berkurangnya nilai arus pengisian.

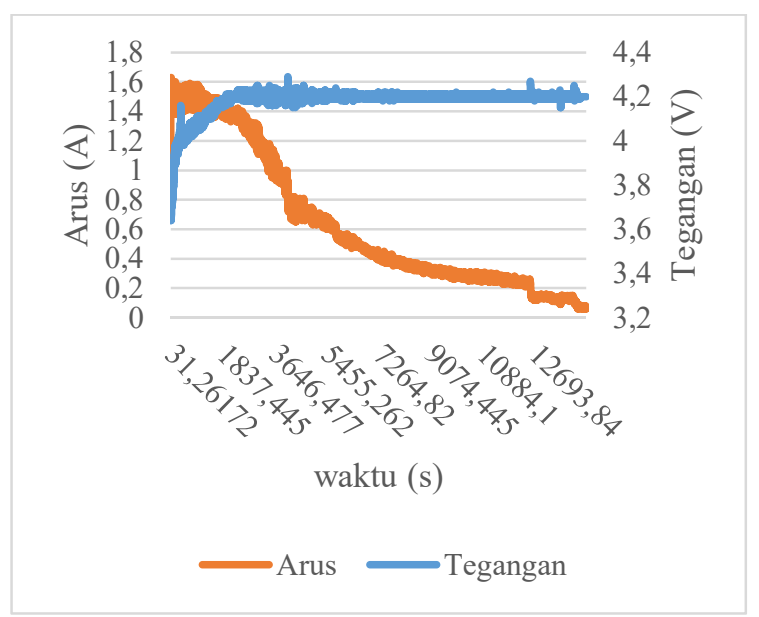

Gambar 14. Grafik Pengisian Baterai 


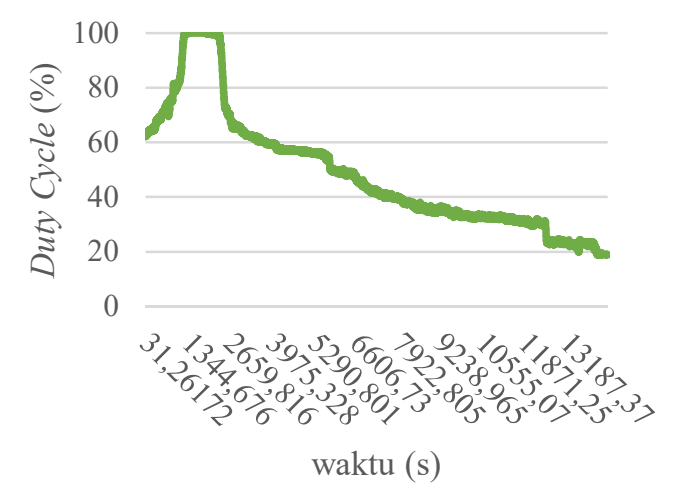

Gambar 15. Grafik Duty Cycle Pengisian Baterai

\section{Kesimpulan}

Berdasarkan perhitungan, simulasi, dan uji coba pada penelitian pengaruh beban dan filter pada penyearah AC-DC terkendali untuk rangkaian pengisi Li-ion berbasis bridge rectifier dan buck converter menggunakan metode $\mathrm{CC} / \mathrm{CV}$ diperoleh beberapa kesimpulan sebagai berikut.

Pada kondisi CC, semakin tinggi nilai beban yang diberikan maka semakin tinggi duty cycle yang dibutuhkan untuk menghasilkan arus keluaran yang sama. Pada kondisi $\mathrm{CV}$, idealnya nilai beban tidak memengaruhi duty cycle yang dibutuhkan. Pada simulasi dan uji coba terdapat beban yang menghasilkan tegangan keluaran tanpa saklar yang berbeda dari nilai idealnya, sehingga menyebabkan nilai duty cycle yang dibutuhkan menjadi berbeda-beda. Hasil yang diperoleh adalah semakin tinggi nilai beban yang digunakan maka semakin rendah duty cycle yang dibutuhkan untuk mendapatkan tegangan keluaran yang sama.

Pengaruh penggunaan filter pada kondisi $\mathrm{CC}$ adalah dapat menurunan nilai ripple dan meningkatkan rectification ratio (RR). Berdasarkan perhitungan matematis, simulasi, dan uji coba yang dilakukan diperoleh pengurangan nilai ripple secara berturut-turut, $46,45 \%, 46,43 \%$, dan $45,46 \%$. Lalu, pada perhitungan matematis, simulasi, dan uji coba yang dilakukan diperoleh peningkatan RR secara berturut-turut $18,17 \%, 18,17 \%$, dan
$21,59 \%$.

Penggunaan filter pada kondisi CV dapat mengurangi nilai ripple dan meningkatkan rectification ratio (RR). Berdasarkan perhitungan matematis, simulasi, dan uji coba diperoleh pengurangan nilai ripple secara berturutturut adalah 46,44\%, 46,6\%, dan 48,78\%. Kemudian, dengan menggunakan perhitungan matematis, simulasi, dan uji coba diperoleh peningkatan RR seecara berturut-turut $18,17 \%, \quad 18,17 \%$ dan 20,99\%.

Pengisian baterai Li-ion dengan kapasitas 3Ah menggunakan rangkaian yang telah dirancang memakan waktu selama 4 jam 58 detik. Dimana waktu pengisian terlama terdapat pada kondisi CV dengan waktu 3 jam 28 menit 48 detik, sedangkan pengisian kondisi $\mathrm{CC}$ terjadi selama 32 menit 10 detik. Pada pengisian $\mathrm{CC}$ terjadi peningkatan nilai duty cycle saat terjadinya peningkatan nilai tegangan baterai. Sedangkan pada pengisian $\mathrm{CV}$, nilai duty cycle akan menurun sejalan dengan berkurangnya nilai arus pengisian.

\section{Saran}

Berdasarkan hasil yang diperoleh pada penelitian ini, diperoleh beberapa saran sebagai berikut. Meningkatkan nilai tegangan masukan sehingga nilai arus pengisian kondisi $\mathrm{CC}$ dapat terjaga konstan ketika tegangan mencapai $4,1 \mathrm{~V}$ atau lebih dan menambahkan sensor suhu untuk mengetahui kondisi suhu baterai saat pengisian.

\section{Daftar Pustaka}

[1] Deng, Da., "Li-ion Batteries: Basics, Progress, and Challenges", Energy Science and Engineering;3(5):385-418, 2015.

[2] Karami, Nabil, dan Nazih M., "Smart Battery Charger Using a Bridgeless Boost AC/DC Converter", IEEE, 2014.

[3] Rashid, Muhammad., "Power Electronics Handbook 4th edition", Elservier Inc., 2018.

[4] Pyakuryal, Sudeep, dan Mohammad Matin., "Filter Design for AC to DC Converter", International Refereed 
Journal of Engineering and Science (IRJES), Vol. 2, Issue 6, pp.42-49, 2013.

[5] Tan, Rodney H.G., dan Landon Y.H.Hoo., "DC-DC Converter Modelling and Simulation using State Space Approach", IEEE, 2015.

[6] Nguyen, Van-Sang, Van-Long Tran, Woojin Choi, dan Dae-wook Kim., "Analysis of the Output Ripple of the DCDC Boost Charger for Li-ion Batteries", Journal of Power Electronics, Vol. 14, No. 1, pp. 135-142, 2014.

[7] Liu, Kailong, Kang Li, Qiao Peng, dan Cheng Zhang., "A brief review on key technologies in the battery management system of electric vehicles", Researchgate, 2018.

[8] Blinov, Andrei, Ievgen Verbytskyi, Denys Zichenko, Dmitri Vinnikov, dan Ilya Galkin., "Modular Battery Charger for Light Electric Vehicles", energies, 2020.

[9] Asiri, Yahya, dan Mohamed Shwehdi., "Performance of Single Phase Full Wave Rectifier Controlled by PWM", Researchgate, 2007.
[10] Hart, Daniel W., "Power Electronics", Mc-Graw-Hill, Inc., 2011.

[11] Halliday, David, Robert Resnick, dan Jearl Walker., "Fundamentals Of Physics $10^{\text {th }}$ Edition", John Wiley \& Sons, Inc., 2014.

[12] Silver, Ward, dan Mark Wilson., "The ARRL Extra Class License Manual $9^{\text {th }}$ edition", American Radio Relay League, 2008.

[13] O’Malley, John., “Schaum's Outline of Theory and Problems of Basic Circuit Analysis", McGraw-Hill, Inc., 1992.

[14] Preston, David C., Barbara E. Shapiro., "Electromyography and Neuromuscular Disorders: Clinical-ElectrophysiologicUltrasound Correlations", Elservier Inc., 2020 . 